\title{
9. CONTRIBUTION OF BANK VOLES TO THE FUNCTIONING OF FOREST ECOSYSTEMS
}

Władysław GRODZINSKI \& Kazimierz PETRUSEWICZ

We can estimate the role of the bank vole in the functioning of temperate zone forest ecosystems largely in terms of the contribution of this species to the total energy and matter flow. Bank voles as small homeothermic consumers have high costs of maintenance and a low net production (see section 8.3). In the trophic web of forest ecosystems they are chiefly primary consumers and only in part secondary consumers (see section 3.1).

Energy flow through Clethrionomys sp. populations has already been studied in a dozen or so forest ecosystems of Europe, North America, and Asia (Grodziński et al., 1969/1970, 1977; Grodziński, 1971, Bobek, 1971, 1973; Hansson, 1971a, 1974c; Aulak, 1973; Kozłowski et al., 1980; Jensen, 1981, Smal \& Fairley, 1981; see also section 7.6). Many of these studies were initiated during the IBP period when the bank vole became a "laboratory mouse" (a model rodent) for ecologists. In all the papers quoted here both production and respiration were estimated for bank vole populations, and most of them also contain data on consumption (sometimes consumption was estimated directly from biomass, e.g. Ryszkowski, 1969/70), but only in some papers was the consumption of bank vole populations compared with the available food supply in their habitat (Table 9.1). Thus, these papers allow us to estimate what bank vole populations remove (consume) from the forest primary production, and also what they can offer themselves to their predators.

Table 9.1. compares the production of bank vole populations in 14 different deciduous, mixed, and coniferous forests, with also the consumption of northern redbacked voles (Clethrionomys rutilus) in a taiga forest. The annual consumption of these populations varied from 1 to $103 \times 10^{3} \mathrm{kcal} / \mathrm{ha}$ year. In open populations of the bank vole a higher consumption was found only in the years of their peak numbers. At that time it reached $192 \times 10^{3} \mathrm{kcal} / \mathrm{ha}$ year in a European deciduous forest and $380 \times 10^{3}$ in an Alaskan spruce forest (Table 9.1). In an isolated population on Crab-Apple island, the density of the bank vole 
population was permanently high, thus the consumption was also high, and it reached $240-332 \times 10^{3} \mathrm{kcal} / \mathrm{ha}$ year (see section 8.6 , Table 8.6).

In relation to the total primary production of these forests, bank vole consumption is negligible as it acconts for a hundredth part of one per cent. It should be remembered, however, that forest production is dominated by wood production. For this reason, it appears to be more reasonable to compare vole consumption with their food available in a forest. Grodziński (1968) defined the food available to small rodents as "food which is easy to find, is being chosen and being eaten by these animals". According to Drożdż (1966), the food available to bank voles in a beech wood comprises the majority of the herb layer vegetation, almost all tree-seeds, buds and twigs of trees, fungi, and some invertebrates. In the case of a beech wood in southern Poland, the food available to bank voles reached about 2 million $\mathrm{kcal} / \mathrm{ha}$ year, nad accounted for only a small fraction of $4.5 \%$ of the total primary production of this forest, which was 44 million $\mathrm{kcal} / \mathrm{ha}$ year (Drożdż, 1966).

Different authors give various estimates of the food available, ranging from about one to a dozen million $\mathrm{kcal} / \mathrm{h}$ a year for various forest types. Available food considerably increased in the years with heavy crops of tree-seeds but then also the bank vole population increased (Bobek, 1971, 1973; Grodziński, 1971; see also section 8.6). The utilization of food resources by consumption in bank vole populations ranges from $0.1 \%$ to $14 \%$, occasionally being higher, but usually on the order of few per cent. It is assumed that small homeothermic consumers destroy at least as much vegetation as they consume (Petrusewicz \& Grodziński, $1973,1975)$, therefore the material removed by bank vole populations would approach $25 \%$ of their available food.

Is this much or not, and what is the importance of vole consumption to the functioning of a forest? The consumption by bank vole populations presented in Table 9.1 usually predominates the total consumption by small rodents in these forests. It is more difficult to compare consumption by small rodents with energy utilization by other consumers. In pine- and deciduous forests of the Niepolomice Forest, the consumption by the bank vole and other small rodents was similar to that by other homeothermic consumers (birds, herbivore ungulates), but one order lower than by phytophagous insects (Górecki et al., 1984).

Even a more important issue is the kind of materials consumed and removal by the bank vole in a forest. A high proportion of their diet consists of seeds and seedlings, and these materials are of great importance to every forest (Golley et al., 1975b). In an Irish oak wood, for example, both voles and mice consumed merely $0.2 \%$ of the primary production, but as much as $7-51 \%$ of the seed and fruit materials 
(Smal \& Fairley, 1981). At the same time, bank voles store and sometimes carry over large distances tree seeds, enhancing in this way forest regrowth. Seedlings are browsed and destroyed by voles during the winter (Hansson, 1974c), and injures by voles can be higher than by fungi and/or insects (Golley et al., 1975b). On the other hand, it should be remebered that insects are a permanent component of the bank vole diet (see section 3.1).

The role of the bank vole in nutrient cycling has been poorly studied. In two forest types of the Niepolomice Forest, the total pool of nutrients in vole and mouse excrements reached 640 and $815 \mathrm{~g} / \mathrm{ha}$ year, while the concentration of nutrients in their bodies was 32 and $41 \mathrm{~g} / \mathrm{ha}$, respectively (Górecki \& Szafranek, 1981). These nutrients consisted of nitrogen, phosphorus, potassium, and calcium. Small rodents recycled in those, two types of forest 600 and $763 \mathrm{~g} \mathrm{~N}, 25$ and $33 \mathrm{~g} \mathrm{P}, 29$ and $37 \mathrm{~g} \mathrm{~K}$, and 17 and 22g Ca per hectare over a year (Górecki \& Szafranek, 1981). These are smaller amounts than those recycled by other consumers in those same forests, but nevertheless important because they are released in a form easily available to reducers. It seems that nutrients passing through the chain of grazing consumers are then rapidly decomposed (Batzli, 1978).

Bank vole production is an important source of food for many raptors and carnivore mammals. Clethrionomys species usually predominate number and biomass the small rodent communities of northtemperate forests. Seasonally their numbers are particularly high in subarctic taiga forests, where one to three redbacked vole species occur (Clethrionomys glareolus, C. rutilus, C. rufocanus, and C. gapperi), usually in cycling populations (Pruitt, 1968; Grodziński, 1971; Koshkina \& Korotkov, 1975; Fuller, 1977; Wiger, 1979).

Mean annual standing crop of bank vole biomass varies from less than $100 \mathrm{~g}$ to $600 \mathrm{~g} / \mathrm{ha}$ (see reviews by Grodziński \& French, 1983). On Crab-Apple island, the standing crop of their biomass over three successive years was higher, reaching 660-945 g/ha (recalculated from section 8.6). An even higher standing crop of the bank vole biomass can occur in seasons of peak population density (Bobek, 1971, 1975), and its estimated value at this time can reach about $1.5-2 \mathrm{~kg} / \mathrm{ha}$ of "vole meat".

Efficiency of net production in bank vole populations is very low, the turnover of these rodents is very high (section 8.2), and digestibility and assimilation are rather high (section 8.5), but at the same time their metobolic rate is extremely high (section 8.4). Recently, the efficiency of production was analysed in relation to respiration and assimilation $(P / R$ and $P / A$ ) for 30 species of small mammals, including bank voles (Gro- 


\section{Table 9.1}

Total consumption (C) in populations of the bank vole (Clethrionomys glareolus - rows 1-14) and the redbacked vole (Clethrionomys rutilus - row 15$)$ as well as percentage of their food available (FA) consumed yearly in various forest ecosystems.

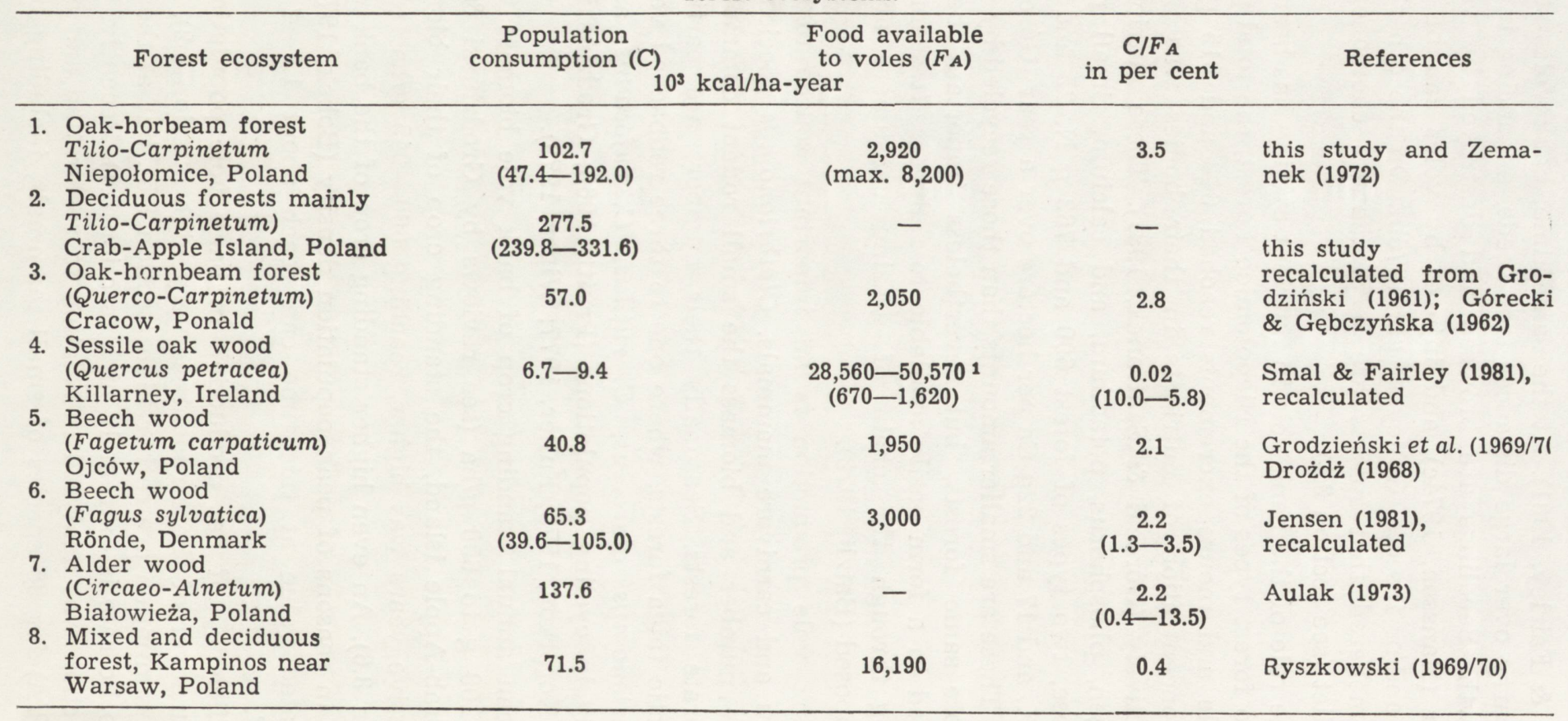


Table 9.1; concluded.

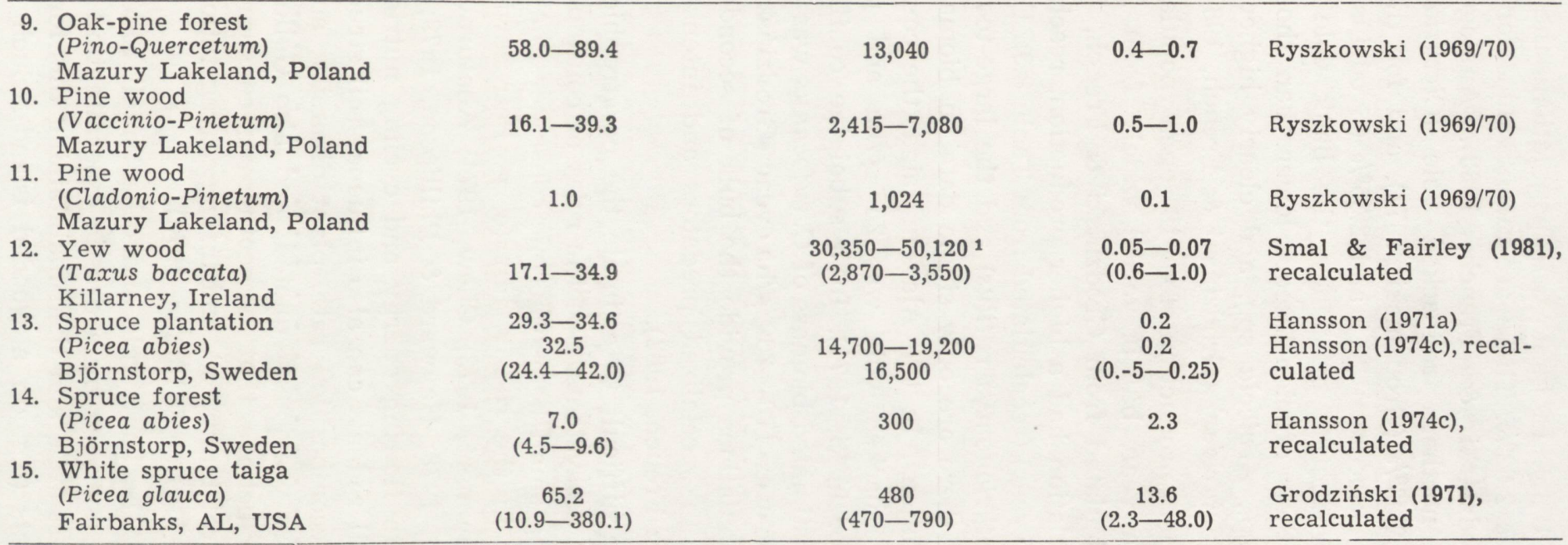

1 Total above-ground primary production (seeds and fruits available to small rodents, in parenthesis). 
dziński \& French, 1983). In bank vole populations the efficiency $P / R$ is $2.70 \%$ and $P / A$ is $2.62 \%$. These are mean values for 18 populations and/or years (Grodziński \& French, 1983). Analogous production efficiencies for the northern redbacked vole (Clethrionomys rutilus) averaged 2.07 and $2.03 \%$ (Grodziński, 1971), and for the large-toothed redbacked vole (C. rufocanus) 2.41 and 2.35\% (Grodziński et al., 1977). With respect to production efficiency, the bank vole are typical of omnivore rodents; their efficiencies are lower than those of herbivore rodents (Microtus sp., Arvicola sp.), and clearly higher than those of granivore rodents (Sciuridae) (Grodziński \& French, 1983).

Mean annual net production for 18 open populations of bank voles was $699 \mathrm{~g} / \mathrm{ha}$ year, but it varied widely from $76 \mathrm{~g}$ to nearly $2 \mathrm{~kg} /$ ha year (recalculated from Grodziński \& French, 1983). Only the isolated island population had a higher production, reaching about $3 \mathrm{~kg}$ $(2.826-3.223 \mathrm{~kg} / \mathrm{ha} \cdot$ year) (recalculated from Table 8.3$)$. For the northern redbacked vole (Clethrionomys rutilus) and the large-toothed redbacked vole (C. rufocanus) there are only single data on biomass and production in their populations. In the Alaskan taiga, the computed biomass of the northern redbacked vole was $265 \mathrm{~g} / \mathrm{ha}$ and production was $760 \mathrm{~g} /$ ha year (Grodziński, 1971). In a subalpine coniferous forest in central Japan, the estimated biomass of C. rufocanus was 55 and $95 \mathrm{~g} / \mathrm{ha}$, and their production was $170-300 \mathrm{~g} / \mathrm{ha} \cdot$ year (Grodziński et al., 1977a). Thus bank vole populations provide the bulk of secondary production, which is available to specialized predators and intensely utilized by them (Ryszkowski \& French, 1982).

It is much more difficult to estimate the paratrophic effects of the bank vole on forest ecosystems. Specific roles of consumers in different ecosystems, including small homeothermic consumers, has been analysed by some ecologists in the rodent last (e. g. Petrusewicz \& Grodzinski, 1973, 1975; Remmert, 1973; Chew, 1974; Abaturov, 1975; Lee \& Inman, 1975; Batzli, 1978; Hayward \& Phillipson, 1979; Górecki et al., 1984). In addition to flowing energy and cycling nutrients, which are discussed here, small rodents can also influence soil structure, transportation of matter, decomposition rate, plant diversity, and spreading of some plants (authors previously quoted, and also Golley et al., 1975). Some authors also believe that homeothermic consumers can act in ecosystems as "control bumpers", and influence vegetation diversity and stability (Turner, 1970; Lee \& Inman, 1975).

The real role of the bank vole and other small rodents in a forest ecosystem could be analysed by a drastic extermination of these pretty animals from a forest area, and then maintaining this forest in isolation, free of small rodents (e.g. on a wooded island). Such an experiment, 
however, would be technically difficult and it should be continued for more than 100 years, this being the duration lof a complete forest succcession in our part of the temperate zone (Grodziński, 1959). Therefore, not waiting with this monograph for such an experiment, let us try to speculate how a forest free of bank voles and other small rodents could function. Such a forest is likely to grow at a slightly lower rate (slower matter cycling), its regrowth should be better, succession more rapid, and species diversity of the herb layer vegetation lower. But such a forest predators would not be so abundant, nad insects, especially on the forest floor, would be less well controlled. 